JURNAL TEKNIK SIPIL (JUTEKS)

Vol. III No. 1, Halaman: 254 - 258

Bulan April 2018

\title{
MODEL INTRNATIONAL ROUGHNESS INDEX VS WAKTU PADA BEBERAPA JALAN NASIONAL DI KOTA KUPANG
}

\author{
Marsinta Simamora ${ }^{1 *}$, Diarto Trisnoyuwono ${ }^{2}$, dan Anastasia H. Muda ${ }^{3}$ \\ ${ }^{1}$ Jurusan Teknik Sipil Politeknik Negeri Kupang \\ *E-mail: m_simamora@pnk.ac.id \\ 2 Jurusan Teknik Sipil Politeknik Negeri Kupang \\ *E-mail: diarto.trisnoyuwono@pnk.ac.id \\ 3 Jurusan Teknik Sipil Politeknik Negeri Kupang \\ EE-mail: anastasia.muda@pnk.ac.id
}

\begin{abstract}
Abstrak
Dalam sistem manajemen infrastruktur, tahap pemeliharaan adalah salah satu bagian yang penting. Biaya penanganan/pemeliharaan jalan yang besar perlu diatasi melalui satu perencanaan pembiayaan. Penelitian ini bertujuan untuk membangun suatu model antara IRI versus waktu pada jalan nasional di wilayah Kota Kupang. Model dibangun berdasarkan data sekunder IRI dan divalidasi menggunakan data primernya. Hasil pemodelan menunjukkan bahwa IRI merupakan fungsi polynomial tingkat -4 dari waktu dengan determinasi $R^{2}=0,9337$ dan 0,8073 masing-masing untuk jalan Pahlawan dan WJ. Lalamentik. Hasil ini dapat digunakan memprediksi biaya pemeliharaan dengan metode memasangkan nilai IRI dan biaya standar yang ada. Dengan demikian untuk beberapa waktu mendatang sudah dapat dipersiapkan biaya yang akan diperlukan dalam rangka mempertahankan kondisi kerataan permukaan jalan.
\end{abstract}

Kata Kunci: model, IRI, dan umur layan jalan

\section{PENDAHULUAN}

Untuk menjaga atau mempertahankan kondisi jalan agar dapat memberikan layanan, paling tidak layanan minimum penerimaan (minimum acceptable level, MAL) diperlukan serangkaian tindakan penanganan dan biaya (Lagaros et al., 2013).

Menurut data dari Departemen Pekerjaan Umum (2013), biaya pengelolaan jalan mengalami trend yang meningkat dari tahun ke tahun. Tahun 2010, 2011, 2012, dan 2013, biaya penanganan untuk total panjang JNnt 38.750 km masing-masing Rp. 18.341 trilyun, Rp. 27.975 trilyun, Rp. 40.339 trilyun, dan Rp. 37,805 trilyun. Yang sering menjadi masalah adalah apakah biaya yang sangat terbatas sudah memberikan hasil yang optimal Dalam satu penelitian dengan menggunakan data sekunder kondisi jalan nasional menunjukkan satu indikasi pengelolaan jalan nasional sangat tidak efektif dan efisien yang diukur menggunakan metode performance jump (PJ) dengan variabel international roughness index (IRI) (Simamora dan Hatmoko, 2014). Keadaan ini menggambarkan bahwa dampak perbaikan jalan terhadap kerataan permukaan tidak efektif.

Penelitian ini bermaksud untuk membangun suatu model kekasaran permukaan jalan di wilayah Nusa Tenggara Timur, khusus di Kota Kupang.

\section{International Roughness Index/IRI}

IRI digunakan untuk mengukur kekasaran permukaan jalan, kekasaran yang diukur pada setiap lokasi diasumsikan mewakili fisik di lokasi tersebut. Menurut Suwardo (2004), tingkat kerataan jalan IRI merupakan salah satu faktor/fungsi pelayanan dari suatu perkerasan jalan yang sangat berpengaruh terhadap kenyamanan pengemudi (riding quality). Ada beberapa penyebab ketidakrataan permukaan jalan, yaitu:

a. Beban lalulintas

b. Efek dari lingkungan

c. Material konstruksi

d. Penyimpangan terhadap proses

konstruksi jalan

Beberapa nilai IRI dan interpretasinya dapat dilihat pada Tabel 1.

Kategori Penanganan Berdasarkan IRI 
Menurut Saleh, dkk (2008) IRI $<4,0$ $\mathrm{m} / \mathrm{km}$ jalan masih dalam tahap pemeliharaan rutin, $\quad I R I=4,0-8 \mathrm{~m} / \mathrm{km}$ perlu dilakukan pemeliharaan berkala (periodic maintenance) yakni dengan pelapisan ulang (overlay), IRI = 8-12 $\mathrm{m} / \mathrm{km}$, perlu dipertimbangkan untuk peningkatan, dan IRI $>12 \mathrm{~m} / \mathrm{km}$ perlu rekonstruksi. Sedangkan menurut Direktorat Jenderal Bina Marga, jenis penanganan berdasarkan nilai IRI dapat dilihat pada Tabel 2.

Tabel 1 Kerataan permukaan perkerasan, IRI dan RCl (Sukirman, 1992)

\begin{tabular}{|c|c|c|c|}
\hline No & $\begin{array}{l}\text { Kategori } \\
\text { Jalan }\end{array}$ & $\begin{array}{c}\text { IRI } \\
\text { maksimum } \\
\mathrm{m} / \mathrm{km}\end{array}$ & $\mathrm{RCl}$ \\
\hline 1 & Jalan Raya & 6,00 & $\begin{array}{l}\text { Baik s/d } \\
\text { sedang }\end{array}$ \\
\hline 2 & $\begin{array}{l}\text { Jalan } \\
\text { Sedang }\end{array}$ & 8,00 & $\begin{array}{l}\text { Baik s/d } \\
\text { sedang }\end{array}$ \\
\hline 3 & Jalan Kecil & 10,00 & $\begin{array}{l}\text { Baik s/d } \\
\text { sedang }\end{array}$ \\
\hline
\end{tabular}

Tabel 2 IRI vs Jenis Penanganan (Bina Marga)

\begin{tabular}{|c|c|c|}
\hline $\begin{array}{l}\text { Kondisi } \\
\text { Jalan }\end{array}$ & IRI (m/km) & $\begin{array}{l}\text { Kebutuhan } \\
\text { Penanganan }\end{array}$ \\
\hline Baik & $\begin{array}{c}\text { IRI rata-rata } \leq \\
4,0\end{array}$ & $\begin{array}{l}\text { Pemeliharaan } \\
\text { rutin }\end{array}$ \\
\hline Sedang & $\begin{array}{c}4,1 \leq \mathrm{IRI} \text { rata- } \\
\text { rata } \leq 8,0\end{array}$ & $\begin{array}{c}\text { Pemeliharaan } \\
\text { berkala }\end{array}$ \\
\hline $\begin{array}{l}\text { Rusak } \\
\text { Ringan }\end{array}$ & $\begin{array}{c}8,0 \leq I R I \text { rata- } \\
\text { rata } \leq 12\end{array}$ & $\begin{array}{l}\text { Peningkatan } \\
\text { jalan }\end{array}$ \\
\hline $\begin{array}{l}\text { Rusak } \\
\text { Berat }\end{array}$ & IRI rata-rata $>12$ & $\begin{array}{c}\text { Peningkatan } \\
\text { jalan }\end{array}$ \\
\hline
\end{tabular}

\section{METODE PENELITIAN}

Penelitian dilaksanakan selama 3 bulan di Kota Kupang. Data yang digunakan adalah data sekunder IRI selama 5 semester yang didapat dari BPJN X sedangkan data primer adalah data IRI untuk satu semester yang diperoleh menggunakan alat NASRA milik BPJN X.

Model dibangun berdasarkan data sekunder menggunakan faslitas excel dengan anggapan bahwa IRI tergantung pada umur layan sebagaimana Pers. 1.

$$
\mathrm{IRI}=f(\mathrm{~T})
$$

Sedangkan model yang akan dibangun diasumsikan sebagaimana pada Pers.2.

$$
\mathrm{Y}=f\left(\mathrm{c}+\mathrm{aX}+\mathrm{bX}^{n}\right)
$$

Di mana :

$\mathrm{Y}=$ Nilai $\mathrm{IRI}(\mathrm{m} / \mathrm{km})$

$\mathrm{X}=\mathrm{T}=$ waktu/periode (per 6 bulan) $\mathrm{n}=$ pangkat tingkat $\mathrm{n}$

$a=$ Koefisien $X$ tingkat satu

$\mathrm{b}=$ Koefisien $\mathrm{X}$ pada tingkat $\mathrm{n}$

$c=$ konstanta

Sementara alat ukur determinasi model digunakan Pers.3 dan 4.

$$
\begin{aligned}
& \varepsilon=\left|\frac{Y-Y^{\prime}}{y \prime}\right| \\
& R^{2}=1-\varepsilon^{2}
\end{aligned}
$$

dimana: $Y=$ data primer $I R I, Y^{\prime}=$ data $I R I$ dari model, $\varepsilon=$ error, $\mathrm{R}^{2}=$ determinasi.

Model yang dipilih adalah yang memiliki determinasi R2 paling besar. Selanjutnya model diuji validitasnya menggunakan data primer. Validitas model diukur berdasarkan tingkat kesalahan data IRI terhadap model yang ditunjukkan oleh determinasi $R^{2}$.

\section{HASIL DAN PEMBAHASAN}

Data sekunder penelitian yang diperoleh dari BPJN X untuk Jl. WJ. Lalamentik dan Jl. Pahlawan dapat dilihat pada Tabel 3 dan 4. Jika diperhatikan data IRI pada JL. WJ. Lalamentik pada tahun 2015 sementer 2 dan tahun 2016 semester 1, terjadi penurunan IRI sementara sejarah penanganan tidak ada. Hal ini menunjukkan bahwa ada anomaly data sebab IRI seharusnya akan makin besar seiring dengan bertambahnya waktu. Hal yang sama terjadi pada JI. Pahlawan pada tahun 2015 semester 1 dan 2. Kualitas data ini akan sangat berpengaryh pada model yang akan dibangun.

Tabel 3 Data Nilai IRI pada JI. WJ. Lalamentik.

\begin{tabular}{cccc}
\hline Tahun & Smtr & $\begin{array}{c}\text { IRI } \\
(\mathrm{m} / \mathrm{km}) \\
(\mathrm{Y})\end{array}$ & $\begin{array}{c}\text { Waktu (X) } \\
\text { (Bulan) }\end{array}$ \\
\hline 2015 & 1 & 3,44 & 6,00 \\
& 2 & 3,76 & 12,00 \\
\hline 2016 & 1 & 3,14 & 18,00 \\
& 2 & 3,70 & 24,00 \\
\hline 2017 & 1 & 3,14 & 30,00 \\
\hline Sumber : BPJN X $(2017)$ & \\
Tabel 4 & Data Nilai IRI pada JI. Pahlawan. \\
\hline \multicolumn{5}{c}{$\begin{array}{c}\text { IRI } \\
\text { Tahun } \\
\text { (m) }\end{array}$} \\
\hline
\end{tabular}




\begin{tabular}{llll}
\hline 2015 & 1 & 3,653 & 6 \\
& 2 & 3,416 & 12 \\
\hline 2016 & 1 & 3,833 & 18 \\
\hline & 2 & 3,836 & 24 \\
\hline 2017 & 1 & 3,833 & 30 \\
\hline
\end{tabular}

Sumber : BPJN X (2017).

Sementara itu data primer IRI yang didapat pada semester 2 tahun 2017 secara berurutan adalah $3,4 \mathrm{~m} / \mathrm{km}$ dan $3,504 \mathrm{~m} / \mathrm{km}$ untuk JI. Pahlawan dan JI. WJ. Lalamentik

\section{Model}

Berdasarkan data yang ada dibangun model IRI terhadap waktu sebagaimana dapat dilihat pada Gambar 1 dan 2 (lampiran). Adapun model yang dipilih adalah model dengan $\mathrm{R}^{2}$ terbesar dari beberapa model yang dicoba. Hasil pemodelan untuk perkerasan jalan . WJ. Lalamentik dapat dilihat pada Tabel 5. Pada Tabel 3, model yang memiliki $R^{2}$ paling besar yaitu 1 adalah No. 5 .

Tabel 5 Bentuk bentuk Persamaan pada JL. WJ. Lalamentik

\begin{tabular}{cccc}
\hline No & Persamaan & $\mathrm{Y}=$ & $\mathrm{R}^{2}$ \\
\hline 1 & Linier & $0,065^{*} \mathrm{~T}+3,635$ & 0,125 \\
\hline 2 & Eksponensial & $3,637 \mathrm{e}^{(-0,02 \mathrm{~T})}$ & 0,133 \\
\hline 3 & Polynomial & $\begin{array}{c}-0,014^{*} \mathrm{~T}^{3}+0,090^{*} \mathrm{~T}^{2} \\
-0,165^{*} \mathrm{~T}+3,594\end{array}$ & 0,202 \\
\hline 4 & Polynomial & $\begin{array}{c}-0,041^{*} \mathrm{~T}^{2}+0,180^{*} \mathrm{~T} \\
+3,348\end{array}$ & 0,193 \\
\hline 5 & \multirow{3}{*}{ Polynomial } & $\begin{array}{c}-0,182^{*} \mathrm{~T}^{4}+2,178^{*} \mathrm{~T}^{3} \\
-8,967^{*} \mathrm{~T}^{2}+14,71^{*} \mathrm{~T}\end{array}$ & 1,000 \\
& & $-4,299$ & \\
\hline
\end{tabular}

Sementara itu hasil pemodelan untuk JL. Pahlawan dapat dilihat pada Tabel 6. Pada Tabel 6, model paling baik adalah No. 2 dengan $R^{2}=1$.

Tabel 6 Bentuk bentuk Persamaan pada JL. Pahlawan

\begin{tabular}{cccc}
\hline No & Persamaan & $\mathrm{Y}=$ & $\mathrm{R}^{2}$ \\
\hline 1 & Polynomial & $\begin{array}{c}-0,055^{*} \mathrm{~T}^{3}+0,498^{*} \mathrm{~T}^{2}- \\
1,243^{*} \mathrm{~T}+4,431\end{array}$ & 0,770 \\
\hline \multirow{3}{*}{2} & Polynomial & $\begin{array}{c}0,061^{*} \mathrm{~T}^{4}-0,793^{*} \mathrm{~T}^{3}+ \\
3,547^{*} \mathrm{~T}^{2}-6,251^{*} \mathrm{~T}+ \\
7,088\end{array}$ & 1,000 \\
\hline
\end{tabular}

\section{Validitas Model}

Selanjutnya validitas model IRI untuk masing-masing jalan diuji menggunakan indikator R2. Dengan menggunakan Pers 3 dan 4 diperoleh $\mathrm{R}^{2}$. Hasil dapat dilihat pada Tabel 7 dan 8. Model pada Jl. Pahlawan memiliki determinasi 0,9337, artinya 93, 37\% IRI dapat dijelaskan oleh umur layan jalan dengan model:

$$
\begin{array}{r}
Y=-0,182 T^{4}+2,178 T^{3}-8,967 T^{2} \\
+14,71 T-4,299
\end{array}
$$

Sementara untuk JI. WJ. Lalamentik persamaan terbaik adalah:

$$
\begin{gathered}
Y=0,061 T^{4}-0,793 T^{3}+3,547 T^{2}-6,251 T \\
+7,088
\end{gathered}
$$

Dengan memasukkan data primer pada masing-masing model diperoleh:

1. Untuk jalan Pahlawan $\mathrm{R}^{2}=0,9337$, dan

2. Untuk JI. WJ. Ialamentik $R^{2}=0,8073$ Hasil ini menunjukkan bahwa model IRI pada JL. Pahlawan lebih baik dari model IRI

\begin{tabular}{|c|c|c|c|c|}
\hline \multicolumn{5}{|l|}{ ERROR (E) } \\
\hline \multicolumn{2}{|c|}{ Data primer } & $|R|=$ & 3,4 & $\mathrm{~m} / \mathrm{km}$ \\
\hline \multicolumn{2}{|c|}{$Y=A+B+C+D+E$} & $\mathrm{~T}=$ & 6 & periode \\
\hline$A=$ & $(235,87)$ & & & (/6 bln) \\
\hline$B=$ & 470,45 & & & \\
\hline$C=$ & $(322,81)$ & & & \\
\hline$D=$ & 88,26 & & & \\
\hline$E=$ & $(4,30)$ & & & \\
\hline$Y=$ & $(4,28)$ & & & \\
\hline$Y(I R I)=$ & 4,275 & & & \\
\hline error $(E)=$ & 0,2573 & & & \\
\hline $\mathrm{e}^{\wedge} 2=$ & 0,06623 & & & \\
\hline$R^{2}=$ & 0,93376 & & & \\
\hline
\end{tabular}
pada JL. WJ. Lalamentik.

Tabel 4.5 Determinasi Model IRI pada Jl.

Pahlawan

\begin{tabular}{|c|c|c|c|c|}
\hline \multicolumn{5}{|l|}{ ERROR (E) } \\
\hline \multicolumn{2}{|c|}{ Data primer } & $|R|=$ & 3,504 & $\mathrm{~m} / \mathrm{km}$ \\
\hline \multicolumn{2}{|c|}{$Y=A+B+C+D+E$} & $T=$ & 6 & periode \\
\hline$A=$ & 79,06 & & & (/6 bln) \\
\hline$B=$ & $(171,29)$ & & & \\
\hline$C=$ & 127,69 & & & \\
\hline$D=$ & $(37,51)$ & & & \\
\hline$E=$ & 7,09 & & & \\
\hline$Y=$ & 5,04 & & & \\
\hline$Y(I R I)=$ & 5,042 & & & \\
\hline $\operatorname{error}(E)=$ & 0,43892 & & & \\
\hline $\mathrm{e}^{\wedge} 2=$ & 0,19265 & & & \\
\hline$R^{2}=$ & 0,807343 & & & \\
\hline
\end{tabular}

Tabel 4.6 Determinasi Model IRI pada JI. WJ. Lalamentik 


\section{PENUTUP}

Model IRI terhadap waktu yang didapat berdasarkan data sekunder tahun 2015-2017 pada ruas JL. WJ. Lalamentik dan Jl. Pahlawan adalah merupakan persamaan polynomial tingkat-4. Hasil validasi terhadap model yang didapat pada kedua ruas jalan menggunakan data primer 1 (satu) semester menunjukkan R2 secara berurutan adalah 0,9337 dan 0,8073 masing-masing untuk Jl. WJ. Lalamentik dan Jl. Pahlawan.

Hasil ini menunjukkan bahwa umur layan jalan dapat menjelaskan perilaku IRI sebesar 93,37\% untuk Jl. WJ. Lalamentik dan $80,73 \%$ untuk JL. Pahlawan.

Namun demikian, karena terjadi anomaly data IRI pada kedua ruas jalan maka model ini tidak dapat digunakan sebagai model pada jalan nasional secara umum di NTT. Oleh karena itu perlu dilakukan pemodelan dengan data yang normal pada penelitian-penelitian selanjutnya.

\section{UCAPAN TERIMAKASIH}

Ucapan terimakasih ditujukan kepada Kementerian Pendidikan, Riset dan Teknologi melalui Politeknik Negeri Kupang atas pembiayaan penelitian yang dilakukan pada Tahun Anggaran 2017 sebesar Rp. 25.500.000,-. Ucapan terima kasih juga disampaikan kepada BPJN X atas bantuannya menyediakan data dan peralatan pada penelitian ini.

\section{DAFTAR PUSTAKA}

Bernold L. E, and AbouRizk S. M., 2010. Managing Performance in Construction. Published by John Wiley \& Sons, Inc., Hoboken, New Jersey Published simultaneously in Canada. ISBN 978-0-470-17164-6.

Ditjen Bina Marga DPU., 2013. Standar biaya penanganan jalan tahun 2011 dan 2012, Sub. Direktorat Informasi dan Komunikasi, Dir. Bina Program, Ditjen. Bina Marga, Kementerian Pekerjaan Umum, Jakarta.

Dong Q., and Huang B., 2011. Evaluation of effectiveness and cost-effectiness of asphalt pavement rehabilitation utilizing LTPP data. Journal of Transportation Engineering, Desember, 2011, doi :10.1061/(ASCE) TE.1943-5436. 0000378.

Eric H., Zimmer D., Hillesland S., 2012,
Overview of the mobility pavement management system (MPMS), Washington State County Road Administration Board, Washington.

Fengxuan, Hu., 2004, Developent of a Direct Type Road Roughness Evaluation System.

Iskandar, A., 1995. Menuju Lalulintas dan Angkutan Jalan Yang Tertib, Direktorat Jendral Perhubungan Darat, Jakarta.

Khurshid, M. B., Irfan, M., and Labi, S., 2011. Optimal performance threshold determination for highway asset intervention: Analitycal framework and application. Journal of Transportation Engineering, Vol. 137 (2), 128-139.

Kubota S., and Mikami I., 2011. Data modelcenter four-dimensional information management system for road maintenance. Journal of Computing in Civil doi:10.1061/(ASCE)CP.19435487.0000176

Lagaros N. D., Kepaptsoglou K., and Karlaftis M. G., 2013. Fund Allocation for Civil Infrastructure Security Upgrade, Journal of Management in Engineering, Vol. 29, No. 2, April 1, 2013. (C) ASCE, ISSN 0742-597, pp. 172-182.

Munehiro K., Takemoto A., Kasai S., and Asano M., 2011, Analysis on rural highway design using traffic microsimulation in cold region, 6th International Symposium on Highway Capacity and Quality of Service, Stockholm, Sweden June 28 - July 1, 2011, Available online at www.sciencedirect.com.

National Cooperative Highway Research Program (NCHRP), 2006. Performance measure and targets for transportation asset management. National Cooperative Highway Research Program Rep. No. 551, Transportation Research Board, National Research Council, Washington, D.C

Sayer, M.W., Gillespie T.D dan Queisoz C.A.V., 1986, The International Road Riding Quality Experiment Establising Correlative and Calibration Standard for Measurement, Technical Paper 45, World Bank, Washington DC.

Simamora M., dan Hatmoko J. U. D., 2014, Efficiency and effectivness of the nontoll national roads management based on the performance jump of pavement condition, Jurnal Dinamika Teknik 
Sipil, Jurusan Teknik Sipil UMS, Surakarta, ecorekayasa@gmail.com, Vol. 10 (1).

Sukirman, S.,1992, Perkerasan Lentur Jalan Raya, Badan Penerbit Nova Bandung.

Suwardo dan Sugiharto., 2004, Tingkat Kerataan Jalan Berdasarkan Alat Rolling Straight edge untuk mengestimasi pelayanan jalan, Universitas Gajah Mada: Yogyakarta.

Sydenham, 2004. System approach to engineering design. Artech House, Inc., ISBN 1-58053-479-1

Underwood B. S., Kim R. Y., and Corley-Lay J., 2011. Assessment of Use of Automated Distress Survey Methods for Network-Level Pavement Management, Journal of Performance of Constructed Facilities, @ASCE, Vol. 25 (3), pp.250-258.

Zhang, H., Keoleian, G. A., and Lepech, M. D., 2012. Net-work level pavement asset management system integrated with life cycle analysis and life cycle optimization. Journal of Infrastructure Systems, doi. 10.1061/(ASCE)/S 1943-555x 0000093. 